Clinical Research Paper

\title{
Pharmacogenomics of platinum-based chemotherapy response in NSCLC: a genotyping study and a pooled analysis
}

\author{
Juan Chen ${ }^{1,2}$, Zhan Wang ${ }^{3}$, Ting Zou ${ }^{1}$, Jiajia Cui ${ }^{1}$, Jiye Yin ${ }^{1,2}$, Wei Zheng ${ }^{1}$, Wuzhong \\ Jiang ${ }^{3}$, Honghao Zhou ${ }^{1,2}$ and Zhaoqian Liu ${ }^{1,2}$ \\ ${ }^{1}$ Department of Clinical Pharmacology, Xiangya Hospital, Central South University, Institute of Clinical Pharmacology, Central \\ South University, Hunan Key Laboratory of Pharmacogenetics, Changsha, P. R. China \\ ${ }^{2}$ Hunan Province Cooperation Innovation Center for Molecular Target New Drug Study, Hengyang, P. R. China \\ ${ }^{3}$ Department of Oncology, Xiangya Hospital, Central South University, Changsha, P. R. China \\ Correspondence to: Zhaoqian Liv, email: liuzhaoqian63@126.com \\ Keywords: platinum, NSCLC, chemotherapy response, meta-analysis, polymorphism \\ Received: March 03, $2016 \quad$ Accepted: May 23, $2016 \quad$ Published: May 29, 2016
}

\section{ABSTRACT}

Published data showed inconsistent results about associations of extensively studied polymorphisms with platinum-based chemotherapy response. Our study aimed to provide reliable conclusions of these associations by detecting genotypes of the SNPs in a larger sample size and summarizing a comprehensive pooled analysis. 13 SNPs in 8 genes were genotyped in 1024 NSCLC patients by SequenomMassARRAY. 39 published studies and our study were included in meta-analysis. Patients with GA or GG genotypes of XRCC1 G1196 had better response than AA genotype carriers (Genotyping study: $\mathrm{OR}=0.72,95 \% \mathrm{CI}$ : $0.53-0.96, P=0.028$; Meta-analysis: $\mathrm{OR}=$ $0.74,95 \%$ CI: $0.62-0.89, P=0.001)$. Patients carrying CT or TT genotypes of XRCC1 C580T could be more sensitive to platinum-based chemotherapy compared to patients with CC genotype (OR $=0.54,95 \% \mathrm{CI}$ : $0.37-0.80, P=0.002$ ). CC genotype of XRCC3 C18067T carriers showed more resistance to platinum-based chemotherapy when compared to those with CT or TT genotypes ( OR $=0.69,95 \% \mathrm{CI}: 0.52-0.91, P=0.009)$. Our study indicated that XRCC1 G1196A/ C580T and XRCC3 C18067T should be paid attention for personalized platinum-based chemotherapy in NSCLC patients.

\section{INTRODUCTION}

Lung cancer is a serious health problem in the whole world for many decades with its highest mortality [1]. It is histologically consisted of small cell lung cancer (SCLC) and non-small cell lung cancer (NSCLC). NSCLC accounts for about $85 \%$ of the total cases. Platinum-based chemotherapy is the standard chemotherapy for first line treatment of NSCLC, especially for advance stage patients [2, 3]. However, the response to platinum-based chemotherapy is greatly variable among individuals, and drug resistance is easily occurred by intrinsic or acquired.

A number of studies suggested single nucleotide polymorphisms (SNPs) may affect chemotherapy response [4-9]. Most of the studies focused on the SNPs of genes in DNA repair pathways or transporters, such as ERCC1, XPD, XRCC1 and MDR1 [10-18]. However, inconsistent results came from different studies on the same issue. For example, Huang et al. and Zhao et al. reported that ERCC1 C8092A may be useful predictive markers for response to platinum-based chemotherapy $[19,20]$, but some other studies showed the contradictory results [21-23]. The same situations were also existed in MDR1 C3435T, XPD A2251C and other SNPs. Although several reviews and meta-analyses summarized the pharmacogenomics of platinum-based chemotherapy response in NSCLC patients [24], they still not reached the consistent conclusion. Moreover, the published meta-analyses were not comprehensive as they usually analyzed only one or several SNPs in their studies $[25,26]$.

In this study, we investigated the relationships between widely studied SNPs and platinum-based chemotherapy response in a larger NSCLC sample size. We also provided a comprehensive meta-analysis on pharmacogenomics of the platinum-based chemotherapy response. Understanding the genetic variants contributed 
to platinum-based chemotherapy will provide guide for individualized chemotherapy and benefit for NSCLC patients.

\section{MATERIALS AND METHODS}

\section{Subjects}

A total of 1024 NSCLC patients were enrolled in our genotyping study. They were from Shanghai Chest, Shanghai Zhongshan, or Shanghai Changhai Hospitals (Shanghai, China) from 2005 to 2010, and Affiliated Cancer Hospital or Xiangya Hospital of Central South University (Changsha, Hunan, China) from 2011 to 2015 (Table 1). The patients to be eligible for the study had to meet the following criteria: (1) histologically or cytologically confirmed NSCLC, and primary tumor in the lung; (2) Patients received platinum-based chemotherapy for at least two cycles, and had no surgery or radiotherapy before. Exclusion criteria included (1) pregnancy or lactation, (2) active infection, (3) symptomatic brain or leptomeningeal metastases, and (4) previous or concomitant other malignancies. Chemotherapy response was evaluated by Response Evaluation Criteria in Solid Tumors (RECIST) 1.1 [27]. Responders were consisted of complete responders (CR) and partial responders (PR) while non-responders including stable disease (SD) and progressive disease (PD). All subjects provided written informed consent, incompliance with the code of ethics of the World Medical Association (Declaration of Helsinki) before this study. The study protocol was approved by the ethics committee of Xiangya School of Medicine, Central South University (registration number: CTXY-1100082). We applied for clinical admission to the Chinese Clinical Trial Registry (registration number: ChiCTRRO-12002873).

\section{SNP selecting, DNA extracting and genotyping}

By considering the meta-analysis of pharmacogenomics of platinum-based chemotherapy in NSCLC, we searched the publications which reported the associations of SNPs with platinum-based chemotherapy response of NSCLC in PubMed database, ISI Web of Knowledge and Cochrane Library. As shown in Figure 1, we found 13 SNPs were widely studied in different publications after systematic literature review. In order to get more reliable results by included more studies and with larger total sample size in the meta-analysis, we did genotyping study about these 13 SNPs in our samples. Information of the 13 SNPs was summarized in Table 2.

Genomic DNA of all subjects was isolated from a $5 \mathrm{~mL}$ peripheral blood sample using the FlexiGene DNA Kit (Qiagen, Hilden, Germany) and stored at -20C until use. Genotyping was conducted by the Sequenom MassARRAY system (Sequenom, San Diego, CA, USA).

\section{Publication search and inclusion criteria}

We did a systematic literature search in PubMed database, ISI Web of Knowledge and Cochrane Library. The identified articles were reviewed carefully to find more relevant articles. The included articles were published before November 23 ${ }^{\text {th }}$ 2015. Keywords for searching the related publications were platinum (platinum, cisplatin, carboplatin, oxaliplatin) and polymorphism (polymorphism, SNP, mutation, variation, single nucleotide polymorphism) and lung cancer.

The inclusion criteria of publications were as follows: (1) studies about platinum-based chemotherapy response; (2) Patients with NSCLC; (3) the data of genotypes in responders and nonresponders could be obtained. Studies were excluded by any one of the following conditions: (1) the data of genotypes could not be provided; (2) articles involved in patients received surgery or radiotherapy.

\section{Data extraction}

All data were extracted independently by two investigators ( $\mathrm{JC}$ and $\mathrm{ZW}$ ) using the same data recording form, but they were blind to each other during the whole extracting process. The discrepancies of the extracted data were discussed and resolved with consensus. The following information were collected from each study: first author's name, publication year, ethnicity, country, sample size, polymorphisms, alleles of the investigated polymorphism, genotyping methods, disease stage, chemotherapy regimen, and the numbers of responders and non-responders in different genotypes.

\section{Statistical analysis}

In our genotyping study, the chi-square and Student $\mathrm{t}$ tests were used to determine the differences in sex, age, smoking status and histology between responders and nonresponders. Unconditional logistic regression was performed to estimate the association of the polymorphisms with chemotherapy response by calculating odds ratios and their $95 \%$ confidence intervals with adjustments. The association study was analyzed in additive, dominant and recessive models. The $P$ value was 2 sided, and $P<0.05$ was considered statistically significant. The aforementioned statistical analyses were performed by PLINK 1.07 [28] and SPSS 18.0 (IBM, Armonk, NY, USA).

In the meta-analysis, the pooled odds ratio (OR) and associated 95\% confidence interval (95\% CI) were 
Table 1: Clinical characteristics of responders and non-responders to platinum-based chemotherapy in NSCLC patients

\begin{tabular}{|l|l|l|}
\hline Characteristics & $\begin{array}{l}\text { Responders }(\%) \\
(\boldsymbol{n}=\mathbf{2 3 7})\end{array}$ & $\begin{array}{l}\text { Non-responders (\%) } \\
(\boldsymbol{n}=\mathbf{7 8 7})\end{array}$ \\
\hline $\begin{array}{l}\text { Sex } \\
\text { Male }\end{array}$ & $\begin{array}{l}174(73.4) \\
63(26.6)\end{array}$ & $\begin{array}{l}550(69.9)) \\
237(30.1)\end{array}$ \\
\hline Agmale & & \\
$<55$ & $81(34.2)$ & $310(39.4)$ \\
$\geq 55$ & $156(63.8)$ & $477(60.6)$ \\
\hline $\begin{array}{l}\text { Smoking status } \\
\text { Non-smoker }\end{array}$ & $101(42.6)$ & $354(45.0)$ \\
Smoker & $136(57.4)$ & $433(55.0)$ \\
\hline $\begin{array}{l}\text { Stage } \\
\text { IIIa-IIIb }\end{array}$ & $92(38.8)$ & $241(30.6)$ \\
IV & $145(61.2)$ & $546(69.4)$ \\
\hline Histology & $145(61.2)$ & $517(65.7)$ \\
Squamous & $92(38.8)$ & $270(34.3)$ \\
Adenocarcinoma & $135(57.0)$ & $357(45.4)$ \\
\hline Chemotherapeutic regimen & $55(23.2)$ & $252(32.0)$ \\
Platinum/gemcitabine & $47(19.8)$ & $178(22.6)$ \\
\hline Platinum/paclitaxel &
\end{tabular}

calculated by using the $\mathrm{Z}$ test. The genetic model was chosen by logistic regression [29]. The heterogeneity of publications in each meta-analysis was assessed by using $\mathrm{Q}$ statistic test, it with a significance level of $P<0.05$. We selected the random-effect model to get the results with a wider CIs if $P<0.05$. Otherwise, the fixed-effect model was used to calculate the pooled ORs and $P$ values $[30,31]$. To further evaluate the extent of heterogeneity between publications, $\mathrm{I}^{2}$ statistic test was also employed, its values of $25 \%, 50 \%$ and $75 \%$ were considered as low, moderate and high heterogeneity respectively [32]. The publication bias was examined by the inverted funnel plots, Begg's test [33]and Egger's test [34]. All calculations were conducted by Stata 12.0 (StataCorp LP, College Station, USA). The $P$ value was 2 sided, and $P<$ 0.05 was considered statistically significant.

\section{RESULTS}

\section{Associations of the Polymorphisms with platinum- based chemotherapy response in genotyping study}

1024 NSCLC patients were enrolled in our genotyping study and their clinical characteristics were summarized in Table 1. All of the patients received platinum-based chemotherapy at least two cycles. 237 of them showed good response while 787 had poor response to the treatment. 13 SNPs attempted to be genotyped by Sequenom's MassARRAY system, but 3 (XRCC1 C580T, CDA A79C, XRCC3 C18067T) of the SNPs were failed in primer design since primers of these 3 SNPs would form heterodimers with other primers. Additionally, 2 SNPs (MDR1 G2677T/A, XPD G934A) were not genotyped successfully in all samples, their genotyping results failed in Hardy-Weinberg equilibrium test. The results of associations between 8 SNPs and platinumbased chemotherapy were shown in Table 3 and Table S1. XRCC1 G1196A was significantly related to the platinum-based chemotherapy response. Patients with GA or GG genotypes were more sensitive to platinum-based chemotherapy. We also conducted subgroup analyses which samples selected by age (55 years old), sex, smoking status, histology or chemotherapy regimen. The results of subgroup analyses were summarized in Table 4. In patients with $<55$ years old, GSTP1 A313G and XPG G3310C were related to the chemotherapy response. In patients with $\geq 55$ years old, ERCC1 C354T was associated with chemotherapy response. MDR1 C3435T, G2677T/A and XPD A2251C showed significant associations in patients of females. XRCC1 G1196A was related to drug response in smoking patients. In AC subgroup, ERCC1 C354T and XPG T138C were associated with platinum sensitivity. In patients with VP treatment, XRCC1 G1196A and MDR1 C3435T were correlated with platinum-based chemotherapy response.

\section{Results of meta-analysis}

\section{Characteristics of eligible studies}

Overall 4014 studies were selected during the first step of systematic literature review about platinum and lung cancer. With further reviewed, there were 475 studies were involved in single nucleotide polymorphisms. After 
Table 2: Polymorphisms involved in the study

\begin{tabular}{|l|l|l|l|}
\hline Pathways & Genes & Polymorphisms & References \\
\hline DNA repair & ERCC1 & C354T (Asn118Asn) & $\begin{array}{l}7,10,11,14,16,17,19- \\
22,41,44,46,51,67,69\end{array}$ \\
\hline & & C8092A (Gln504Lys) & $16,17,19-23,47,51$ \\
\hline Detoxification & GSTP1 & A313G (Ile105Val) & $7,15,38,51,65,67$ \\
\hline Transporter & MDR1 & C3435T (Ile154Ile) & $10,11,13,18,39$ \\
\hline & & G2677T/A (Ala893Ser/Thr) & $10,13,18$ \\
\hline DNA repair & XPD & A2251C (Lys751Gln) & $7,11,12,21,22,35,41-49,51,69$ \\
\hline & & G934A (Asp312Asn) & $7,11,12,22,43-45,48,49,51,69$ \\
\hline DNA repair & XPG & G3310C (His1104Asp) & $8,36,38$ \\
\hline & & T138C (His46His) & $8,9,36,38$ \\
\hline DNA repair & XRCC1 & G1196A (Arg399Gln) & $7,15,22,36-38,40,46,50-52$ \\
\hline & & C580T (Arg194Trp) & $35-38,40,52$ \\
\hline DNA repair & XRCC3 & C18067T (Lys27Gln) & $7,22,36,41,42,52$ \\
\hline Metabolism & CDA & A79C (Thr241Met) & $7,41,45,69$ \\
\hline
\end{tabular}

Table 3: Association of XRCC1 G1196A with platinum-based chemotherapy response in our genotyping study

\begin{tabular}{|l|l|l|l|l|l|l|l|l|l|l|}
\hline Gene & Polymorphisms & Genotype & Responders & $\begin{array}{l}\text { Non- } \\
\text { responders }\end{array}$ & Additive & \multicolumn{1}{l|}{ Dominant } & \multicolumn{3}{l|}{ Recessive } \\
\hline & & & $N(\%)$ & $N(\%)$ & OR(95\%CI) & P value & OR(95\%CI) & P value & OR(95\%CI) & $\begin{array}{l}P \\
\text { value }\end{array}$ \\
\hline XRCC1 & G1196A & GG & $104(43.9)$ & $400(50.8)$ & $0.80(0.63-1.02)$ & 0.072 & $0.72(0.53-0.96)$ & $0.028^{*}$ & $0.99(0.54-1.80)$ & 0.968 \\
\hline & & GA & $110(46.4)$ & $292(37.1)$ & & & & & & \\
\hline & & AA & $15(6.3)$ & $47(6.0)$ & & & & & & \\
\hline
\end{tabular}

$* P<0.05$

Table 4: Stratification analyses of the associations of polymorphisms and platinum-based chemotherapy response in our genotyping study

\begin{tabular}{|c|c|c|c|c|c|c|c|c|}
\hline \multirow[t]{2}{*}{ Gene } & \multirow{2}{*}{ Polymorphisms } & \multirow[t]{2}{*}{ Subgroups } & \multicolumn{2}{|l|}{ Additive } & \multicolumn{2}{|l|}{ Dominant } & \multicolumn{2}{|l|}{ Recessive } \\
\hline & & & OR(95\%CI) & $P$ value & OR(95\%CI) & $P$ value & OR(95\%CI) & $P$ value \\
\hline GSTP1 & rs 1695 & $<55$ & $2.03(1.18-3.46)$ & $0.010^{*}$ & $2.36(1.29-4.28)$ & $0.005^{*}$ & $1.49(0.32-6.88)$ & 0.607 \\
\hline XPG & rs 17655 & $<55$ & $0.68(0.47-0.98)$ & $0.038^{*}$ & $0.44(0.23-0.86)$ & $0.016^{*}$ & $0.76(0.43-1.35)$ & 0.348 \\
\hline ERCC1 & rs11615 & $\geq 55$ & $1.65(1.15-2.36)$ & $0.006^{*}$ & $1.59(1.05-2.41)$ & $0.028^{*}$ & $5.13(1.20-21.98)$ & $0.028^{*}$ \\
\hline XPD & rs13181 & Females & $4.95(1.08-22.72)$ & $0.040^{*}$ & $4.95(1.08-22.72)$ & $0.040 *$ & & \\
\hline MDR1 & rs 1045642 & Females & $0.67(0.46-0.99)$ & $0.048 *$ & $0.55(0.30-1.00)$ & 0.052 & $0.63(0.31-1.27)$ & 0.194 \\
\hline MDR1 & rs2032582 & Females & $1.43(0.98-2.09)$ & 0.065 & $1.27(0.68-2.37)$ & 0.453 & $2.44(1.17-5.05)$ & $0.017 *$ \\
\hline XRCC1 & rs 25487 & Smokers & $0.74(0.53-1.02)$ & 0.063 & $0.64(0.43-0.94)$ & $0.024 *$ & $1.01(0.56-1.81)$ & 0.945 \\
\hline ERCC1 & rs11615 & $\mathrm{AC}$ & $1.85(1.17-2.92)$ & $0.009^{*}$ & $2.05(1.18-3.58)$ & $0.011^{*}$ & $2.73(0.79-9.40)$ & 0.112 \\
\hline XPG & rs 1047768 & $\mathrm{AC}$ & $0.53(0.36-0.77)$ & $0.001 *$ & $0.52(0.32-0.86)$ & $0.010^{*}$ & $0.30(0.13-0.65)$ & $0.003 *$ \\
\hline XRCC1 & rs 25487 & VP & $0.62(041-1.15)$ & 0.148 & $0.49(0.25-0.95)$ & $0.035^{*}$ & $1.71(0.36-8.07)$ & 0.496 \\
\hline MDR1 & rs 1045642 & VP & $0.62(0.39-0.99)$ & $0.047 *$ & $0.70(0.35-1.42)$ & 0.325 & $0.34(0.15-0.78)$ & $0.011 *$ \\
\hline
\end{tabular}

NSCLC: Non-Small Cell Lung Cancer; VP: Navelbine/Platinum; AC: Adenocarcinoma $* P<0.05$ 
Table 5: Characteristics of eligible publications considered in the meta-analysis

\begin{tabular}{|c|c|c|c|c|c|c|c|c|}
\hline Authors & Year & Ethnicity(Country) & \begin{tabular}{|l|}
$\begin{array}{l}\text { Number } \\
\text { of } \\
\text { patients }\end{array}$ \\
\end{tabular} & $\begin{array}{l}\text { Disease } \\
\text { stage }\end{array}$ & $\begin{array}{l}\text { Chemotherapy } \\
\text { regimans }\end{array}$ & $\begin{array}{l}\text { Genotyping } \\
\text { methods }\end{array}$ & $\begin{array}{l}\text { Genes and } \\
\text { polymorphisms }\end{array}$ & $\begin{array}{l}\text { Reference } \\
\text { number }\end{array}$ \\
\hline Ryu et al. & 2003 & Asian (Korea) & 109 & IIIB-IV & $\begin{array}{l}\text { cisplatin-based } \\
\text { chemotherapy }\end{array}$ & $\begin{array}{l}\text { SNaPShot } \\
\text { assay }\end{array}$ & $\begin{array}{l}\text { ERCC1 } \\
\text { C354T,XPD } \\
\text { A2251C,XPD } \\
\text { G934A }\end{array}$ & 44 \\
\hline Isla et al. & 2004 & Caucasian (Spain) & 62 & IIIB-IV & $\begin{array}{l}\text { cisplatin- } \\
\text { docetaxel }\end{array}$ & TaqMan & $\begin{array}{l}\text { ERCC1 } \\
\text { C354T,XPD } \\
\text { A2251C,XPD } \\
\text { G934A,MDR1 } \\
\text { C3435T }\end{array}$ & 11 \\
\hline Yuan et al. & 2005 & Asian (China) & 151 & IIIB-IV & $\begin{array}{l}\begin{array}{l}\text { platinum-based } \\
\text { chemotherapy }\end{array} \\
\end{array}$ & PCR-RFLP & \begin{tabular}{|l} 
XPD A2251C, \\
ERCC1 C8092A
\end{tabular} & 47 \\
\hline $\begin{array}{l}\text { Booten et } \\
\text { al. }\end{array}$ & 2006 & $\begin{array}{ll}\text { Caucasian } & \text { (United } \\
\text { Kingdom) } & \end{array}$ & 89 & III-IV & $\begin{array}{l}\text { platinum-based } \\
\text { chemotherapy }\end{array}$ & $\begin{array}{l}\text { Direct } \\
\text { sequencing }\end{array}$ & GSTP1 A313G & 65 \\
\hline Yuan et al. & 2006 & Asian (China) & 200 & IIIB-IV & $\begin{array}{l}\text { platinum-based } \\
\text { chemotherapy }\end{array}$ & PCR-RFLP & $\begin{array}{l}\text { XPD } \quad \text { A2251C, } \\
\text { XRCC1 C580T }\end{array}$ & 35 \\
\hline $\begin{array}{l}\text { Booton et } \\
\text { al. }\end{array}$ & 2006 & $\begin{array}{|ll|}\text { Caucasian } & \text { (United } \\
\text { Kingdom) } & \\
\end{array}$ & 89 & III-IV & $\begin{array}{l}\text { platinum-based } \\
\text { chemotherapy }\end{array}$ & PCR-RFLP & $\begin{array}{l}\text { XPD A2251C,XPD } \\
\text { G934A }\end{array}$ & 12 \\
\hline Pan et al. & 2008 & Asian (China) & 69 & IIIB-IV & $\begin{array}{l}\text { cisplatin- } \\
\text { vinorelbine }\end{array}$ & PCR-RFLP & $\begin{array}{l}\text { MDR1 } \\
\text { C3435T,MDR1 } \\
\text { G2677T }\end{array}$ & 18 \\
\hline Sun et al. & 2008 & Asian (China) & 87 & IV & $\begin{array}{l}\text { platinum-based } \\
\text { chemotherapy }\end{array}$ & \begin{tabular}{|l|} 
DD \\
polyacrylamide \\
gel-based DNA \\
microarray \\
\end{tabular} & $\begin{array}{l}\text { XPG G3310C,XPG } \\
\text { T138C,XRCC1 } \\
\text { G1196A,XRCC1 } \\
\text { C580T } \\
\end{array}$ & 38 \\
\hline $\begin{array}{l}\text { Tibaldi et } \\
\text { al. }\end{array}$ & 2008 & Caucasian (Italy) & 65 & IIIB-IV & $\begin{array}{l}\text { cisplatin- } \\
\text { gemcitabine }\end{array}$ & $\begin{array}{l}\text { Taqman probe-- } \\
\text { based assays }\end{array}$ & $\begin{array}{l}\text { ERCC1 C354T, } \\
\text { XPD A2251C,XPD } \\
\text { G934A,CDA A79C }\end{array}$ & 69 \\
\hline Hong et al. & 2009 & Asian (China) & 164 & III-IV & $\begin{array}{l}\text { cisplatin- } \\
\text { vinorelbine }\end{array}$ & PCR-RFLP & $\begin{array}{l}\text { XRCC1 } \\
\text { G1196A,XRCC1 } \\
\text { C580T }\end{array}$ & 40 \\
\hline $\begin{array}{l}\text { Kalikaki et } \\
\text { al. }\end{array}$ & 2009 & Caucasian (Greece) & 119 & IIIA-IV & $\begin{array}{l}\text { platinum-based } \\
\text { chemotherapy }\end{array}$ & $\begin{array}{l}\text { PCR-RFLP } \\
\text { Direct } \\
\text { sequencing }\end{array}$ & $\begin{array}{l}\text { ERCC1 } \\
\text { C354T,ERCC1 } \\
\text { C8092A,XPD } \\
\text { A2251C,XPD } \\
\text { G934A,XRCC1 } \\
\text { G1196A,GSTP1 } \\
\text { A313G }\end{array}$ & 51 \\
\hline Pan et al. & 2009 & Asian (China) & 54 & IIIB-IV & $\begin{array}{l}\text { cisplatin- } \\
\text { docetaxel }\end{array}$ & PCR-RFLP & $\begin{array}{l}\text { MDR1 C3435T, } \\
\text { MDR1 G2677T }\end{array}$ & 13 \\
\hline Sun et al. & 2009 & Asian (China) & 113 & IIIA-IV & $\begin{array}{l}\text { platinum-based } \\
\text { chemotherapy }\end{array}$ & \begin{tabular}{|l|} 
3-D \\
polyacrylamide \\
gel-based DNA \\
microarray \\
\end{tabular} & GSTP1 A313G & 38 \\
\hline Feng et al. & 2009 & Asian (China) & 115 & III-IV & $\begin{array}{l}\text { platinum-based } \\
\text { chemotherapy }\end{array}$ & \begin{tabular}{|l|}
$\begin{array}{l}\text { Gelbased DNA } \\
\text { microarray }\end{array}$ \\
\end{tabular} & XPG T138C & 9 \\
\hline Chen et al. & 2010 & Asian (China) & 95 & IIIB-IV & $\begin{array}{l}\text { cisplatin-based } \\
\text { chemotherapy }\end{array}$ & $\begin{array}{l}\text { ligase detection } \\
\text { reactions }\end{array}$ & $\begin{array}{l}\text { ERCC1 } \\
\text { C354T,MDR1 } \\
\text { C3435T,MDR1 } \\
\text { G2677T } \\
\end{array}$ & 10 \\
\hline Li F et al. & 2010 & Asian (China) & 115 & IIIB-IV & $\begin{array}{l}\text { platinum-based } \\
\text { chemotherapy }\end{array}$ & \begin{tabular}{|l|} 
3-D \\
polyacrylamide \\
gel-based DNA \\
microarray \\
\end{tabular} & $\begin{array}{l}\text { ERCC1 } \\
\text { C354T,ERCC1 } \\
\text { C8092A,XPD } \\
\text { A2251C }\end{array}$ & 21 \\
\hline Wang et al. & 2010 & Asian (China) & 90 & IIIB-IV & $\begin{array}{l}\text { cisplatin-based } \\
\text { chemotherapy }\end{array}$ & $\begin{array}{l}\text { Direct } \\
\text { sequencing }\end{array}$ & $\begin{array}{l}\text { ERCC1 } \\
\text { C354T,ERCC1 } \\
\text { C8092A }\end{array}$ & 16 \\
\hline $\begin{array}{l}\text { Joerger et } \\
\text { al. }\end{array}$ & 2011 & $\begin{array}{l}\text { Caucasian } \\
\text { (Netherlands) }\end{array}$ & 137 & IIIB-IV & $\begin{array}{l}\text { platinum- } \\
\text { gemcitabine }\end{array}$ & $\begin{array}{l}\text { DNA } \\
\text { sequencing }\end{array}$ & \begin{tabular}{l|} 
ERCC1 \\
C354T,XPD \\
A2251C,XPD \\
G934A,XRCC1 \\
G1196A,XRCC3 \\
C18067T,GSTP1 \\
A313G,CDA A79C \\
\end{tabular} & 7 \\
\hline
\end{tabular}




\begin{tabular}{|c|c|c|c|c|c|c|c|c|}
\hline $\begin{array}{l}\text { KimCurran } \\
\text { et al. }\end{array}$ & 2011 & Asian (China) & 300 & IIIB-IV & $\begin{array}{l}\text { cisplatin-based } \\
\text { chemotherapy }\end{array}$ & RT-PCR & ERCC1 C8092A & 23 \\
\hline $\begin{array}{l}\text { Ludovini et } \\
\text { al. }\end{array}$ & 2011 & Caucasian (Italy) & 192 & IIIB-IV & $\begin{array}{l}\text { cisplatin-based } \\
\text { chemotherapy }\end{array}$ & Taqman & $\begin{array}{l}\text { ERCC1 } \\
\text { C354T,XPD } \\
\text { A2251C,CDA } \\
\text { A79C,XRCC3 } \\
\text { Thr241Met }\end{array}$ & 41 \\
\hline Zhou et al. & 2011 & Asian (China) & 111 & IV & $\begin{array}{l}\text { platinum-based } \\
\text { chemotherapy }\end{array}$ & PCR-RFLP & $\begin{array}{l}\text { GSTP1 } \\
\text { A313G,XRCC1 } \\
\text { G1196A }\end{array}$ & 52 \\
\hline $\mathrm{Xu}$ et al. & 2011 & Asian (China) & 130 & IIIB-IV & $\begin{array}{l}\text { platinum-based } \\
\text { chemotherapy }\end{array}$ & PCR-RFLP & $\begin{array}{l}\text { XRCC1 rs25487 } \\
\text { G1196A,XRCC1 } \\
\text { rs1799782 } \\
\text { C580T,XRCC3 } \\
\text { C18067T }\end{array}$ & 39 \\
\hline Yan et al. & 2011 & Asian (China) & 103 & IIIB-IV & $\begin{array}{l}\text { platinum-based } \\
\text { chemotherapy }\end{array}$ & RT-PCR & MDR1 C3435T & 15 \\
\hline Li D et al. & 2012 & Asian (China) & 89 & IIIA-IV & $\begin{array}{l}\text { cisplatin-based } \\
\text { chemotherapy }\end{array}$ & $\begin{array}{l}\text { Gene } \\
\text { sequencing } \\
\text { analysis } \\
\text { technique }\end{array}$ & $\begin{array}{l}\text { ERCC1 } \\
\text { C354T,XPD } \\
\text { A2251C,XRCC1 } \\
\text { G1196A }\end{array}$ & 46 \\
\hline $\begin{array}{l}\text { Krawczyk } \\
\text { et al. }\end{array}$ & 2012 & Caucasian (Poland) & 43 & IIIB-IV & $\begin{array}{l}\text { platinum-based } \\
\text { chemotherapy }\end{array}$ & PCR-RFLP & ERCC1 C354T & 14 \\
\hline Liao et al. & 2012 & Asian (China) & 62 & IIIB-IV & $\begin{array}{l}\text { cisplatin-based } \\
\text { chemotherapy }\end{array}$ & $\begin{array}{l}\text { SNPstream } \\
\text { UHT }\end{array}$ & $\begin{array}{l}\text { ERCC1 } \\
\text { C354T,ERCC1 } \\
\text { C8092A,XPD } \\
\text { A2251C,XPD } \\
\text { G934A,XRCC1 } \\
\text { G1196A,XRCC3 } \\
\text { C18067T }\end{array}$ & 22 \\
\hline Wu et al. & 2012 & Asian (China) & 353 & IIIA-IV & $\begin{array}{l}\text { platinum-based } \\
\text { chemotherapy }\end{array}$ & $\begin{array}{l}\text { Sequenom } \\
\text { MassARRAY }\end{array}$ & $\begin{array}{l}\text { XPD A2251C,XPD } \\
\text { G934A }\end{array}$ & 49 \\
\hline Chen et al. & 2012 & Asian (China) & 256 & IIIB-IV & $\begin{array}{l}\text { platinum-based } \\
\text { chemotherapy }\end{array}$ & PCR-RFLP & \begin{tabular}{|lr} 
XPD & A2251C, \\
XRCC3 & C18067T \\
\end{tabular} & 42 \\
\hline Hong et al. & 2013 & Asian (China) & 135 & IIIB-IV & $\begin{array}{l}\text { platinum-based } \\
\text { chemotherapy }\end{array}$ & TaqMan assays & \begin{tabular}{|l} 
ERCC1 \\
C354T,ERCC1 \\
C8092A \\
\end{tabular} & 17 \\
\hline Huang et al. & 2013 & Asian (China) & 187 & IIIA-IV & $\begin{array}{l}\text { platinum-based } \\
\text { chemotherapy }\end{array}$ & MassARRAY & \begin{tabular}{|l} 
ERCC1 \\
C354T,ERCC1 \\
C8092A
\end{tabular} & 19 \\
\hline Li X et al. & 2013 & Asian (China) & 496 & IIIA-IV & $\begin{array}{l}\text { platinum-based } \\
\text { chemotherapy }\end{array}$ & $\begin{array}{l}\text { Sequenom } \\
\text { MassARRAY }\end{array}$ & $\begin{array}{l}\text { XPD A2251C,XPD } \\
\text { G934A } \\
\end{array}$ & 48 \\
\hline Zhang et al. & 2013 & Asian (China) & 451 & IIIA-IV & $\begin{array}{l}\text { platinum-based } \\
\text { chemotherapy }\end{array}$ & TaqMan & $\begin{array}{l}\text { XPG G3310C,XPG } \\
\text { T138C } \\
\end{array}$ & 8 \\
\hline Lv et al. & 2014 & Asian (China) & 91 & IIIB-IV & $\begin{array}{l}\text { cisplatin-based } \\
\text { chemotherapy }\end{array}$ & TaqMan-MGB & $\begin{array}{l}\text { ERCC1 } \\
\text { C354T,GSTP1 } \\
\text { A313G } \\
\end{array}$ & 67 \\
\hline Peng et al. & 2014 & Asian (China) & 235 & IIIA-IV & $\begin{array}{l}\text { cisplatin-based } \\
\text { chemotherapy }\end{array}$ & PCR-RFLP & XRCC1 G1196A & 50 \\
\hline Zhang et al. & 2014 & Asian (China) & 375 & IIIA-IV & $\begin{array}{l}\text { platinum-based } \\
\text { chemotherapy }\end{array}$ & $\begin{array}{l}\text { Sequenom } \\
\text { MassARRAY }\end{array}$ & \begin{tabular}{|l|} 
XRCC1 \\
G1196A,XRCC1 \\
C580T \\
\end{tabular} & 37 \\
\hline Zhao et al. & 2014 & Asian (China) & 162 & IIIA-IV & $\begin{array}{l}\text { platinum-based } \\
\text { chemotherapy }\end{array}$ & MassARRAY & \begin{tabular}{|lr} 
ERCC1 C354T, \\
ERCC1 C8092A \\
\end{tabular} & 20 \\
\hline Zhou et al. & 2014 & Asian (China) & 93 & IIIB-IV & $\begin{array}{l}\text { cisplatin-based } \\
\text { chemotherapy }\end{array}$ & PCR-RFLP & $\begin{array}{l}\text { XPD A2251C,XPD } \\
\text { G934A,CDA A79C }\end{array}$ & 45 \\
\hline Jin et al. & 2014 & Asain(China) & 378 & I-IV & $\begin{array}{l}\text { cisplatin-based } \\
\text { chemotherapy }\end{array}$ & PCR-RFLP & $\begin{array}{l}\text { XPG G3310C,XPG } \\
\text { T138C,XRCC1 } \\
\text { G1196A,XRCC1 } \\
\text { C580T,XRCC3 } \\
\text { C18067T } \\
\end{array}$ & 36 \\
\hline Li P et al. & 2015 & Asian (China) & 142 & IIIB-IV & $\begin{array}{l}\text { cisplatin- } \\
\text { Vinorelbine }\end{array}$ & PCR-RFLP & $\begin{array}{l}\text { XPD A2251C,XPD } \\
\text { G934A }\end{array}$ & 43 \\
\hline
\end{tabular}


reviewing the abstracts, 32 reviews or meta-analyses and 306 irrelevant studies were excluded. After reading the full texts of the 137 articles which left for reviewed in next step, we found that 41 articles focused on prognosis or toxicity of platinum-based chemotherapy, 21 lacked enough information, 19 were in vitro studies, 9 were about small cell lung cancer, 7 involved in patients with surgery or radiotherapy, and 1 was duplicated publication. Finally, there were 39 publications and our genotyping study included in meta-analysis. The publications included 13 SNPs in 8 genes (Figure 1). The characteristics of these studies were summarized in Table 5. Funnel plot, Begg's test and Egger's test were used to estimate publication bias among the included studies. Visual inspection of the funnel plot of SNPs revealed a symmetrical inverted V shape (Figure S1).

\section{Pooled analysis of chemotherapy response}

The pooled estimate results of the 13 SNPs were shown in Figure 2 and Figure S2. 6 studies examined the association of XRCC1 C580T with platinum sensitivity in NSCLC patients [35-40]. It included 1343 subjects which 650 carried CC genotype and 693 with CT+TT genotype. We chose random-effect model since there was heterogeneity across the studies $\left(P=0.026, \mathrm{I}^{2}=61.3 \%\right)$. Pooled data showed there was significant relationship between XRCC1 C580T and drug response (OR $=0.54$, 95\%CI: $0.37-0.80, P=0.002$ ) (Figure 2A). Patients of XRCC1 C580T CT and TT carriers had better response than CC carriers. Meta-analysis of XRCC3 C18067T included 6 studies [7, 22, 36, 39, 41, 42]. There was no heterogeneity across these studies $\left(P=0.427, \mathrm{I}^{2}=0 \%\right)$, thus we chose fixed-effect model. Pooled data contained 1234 NSCLC patients, 408 were responders and 826 were non-responders. The pooled estimated result showed that this polymorphism was significantly correlated with chemotherapy response $(\mathrm{OR}=0.69,95 \% \mathrm{CI}$ : $0.52-0.91$, $P=0.009$ ) (Figure 2B). XRCC3 C18067T CT and TT genotypes carriers showed better drug response. However, no significant associations were found between the other polymorphisms and chemotherapy response (Figure S2).

\section{Stratified analyses of chemotherapy response}

Since moderate or high heterogeneity was showed in pooled analysis of several SNPs, and for considering that ethnic differences and different chemotherapy regimen may contribute to the drug response, we conducted stratified analyses of Asian, Caucasian and cisplatinbased chemotherapy. It was interesting to found that XPD A2251C was significantly correlated with platinum response in Asian population by pooling 12 studies [7, $21,22,35,42-49]$ included 2570 subjects $(\mathrm{OR}=1.29$, 95\%CI: 1.03-1.62, $P=0.026$ ) (Figure 3A). Patients of Asians with XPD A2251C AA genotype could be more sensitive to platinum-based chemotherapy. XRCC3 C18067T was significantly related to drug response in Caucasian population $(\mathrm{OR}=0.50,95 \% \mathrm{CI}$ : $0.30-0.85$, $P=0.011$ ) (Figure 3B). Patients of Caucasians with CT and TT genotypes of this polymorphism had better drug response. By only pooling the investigations that patients received cisplatin-based chemotherapy, MDR1 C3435T and MDR1 G2677T/A were significantly correlated to

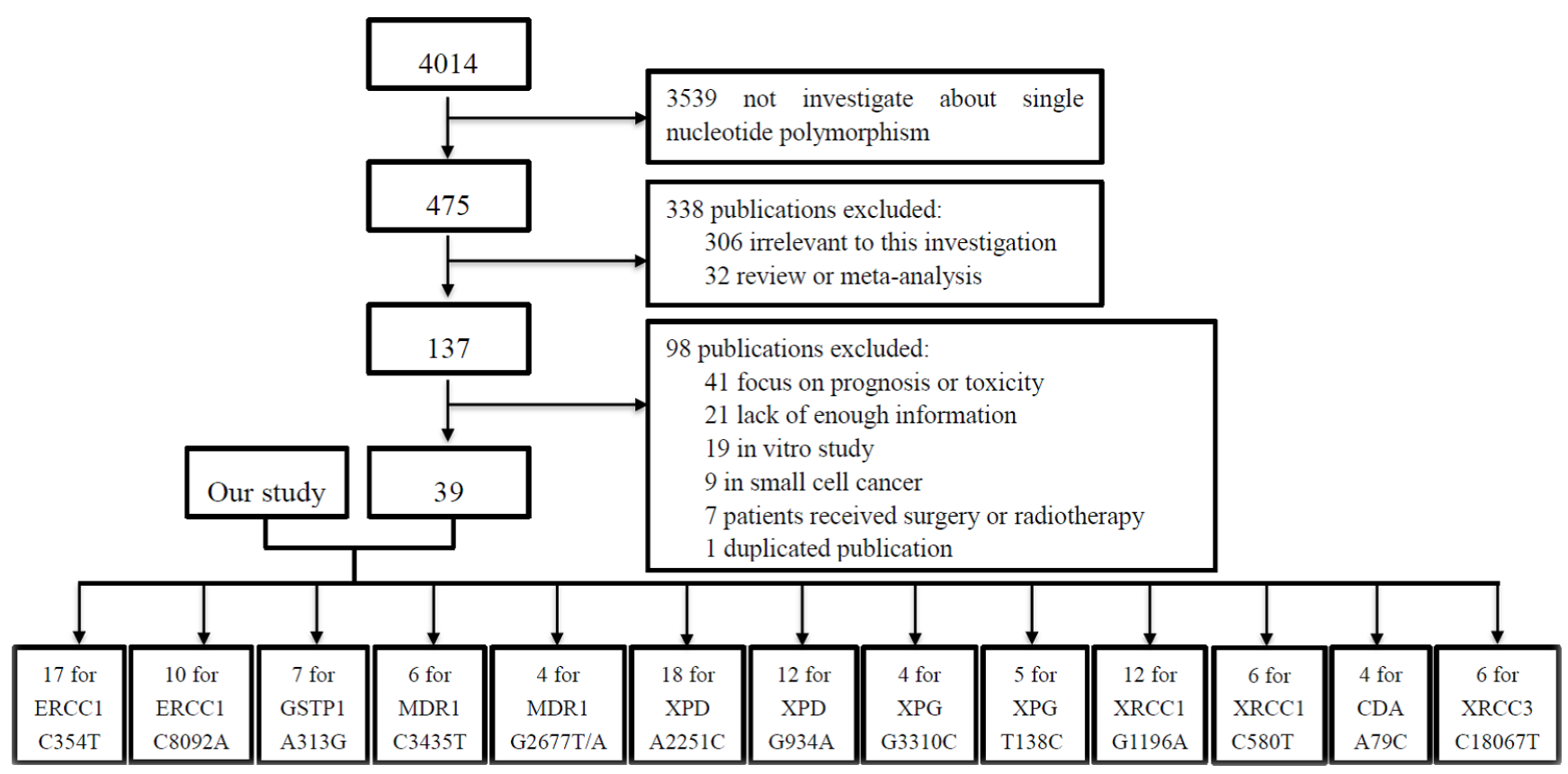

Figure 1: Flow chart of literature selection. 
Table 6: Quality assessment of meta-analysis results

\begin{tabular}{|c|c|c|c|c|c|c|c|}
\hline \multirow[b]{2}{*}{ Genes } & \multirow[b]{2}{*}{ SNPs } & \multirow{2}{*}{$\begin{array}{l}\text { Total pooled } \\
\text { analysis } \\
\text { reliability } \\
\text { (score) }\end{array}$} & \multicolumn{5}{|c|}{ Subgroup analysis reliability (score) } \\
\hline & & & $\begin{array}{l}\text { High quality } \\
\text { studies }\end{array}$ & $\begin{array}{l}\text { Low quality } \\
\text { studies }\end{array}$ & Asian & Caucasian & Cisplatin \\
\hline \multirow[t]{2}{*}{ ERCC1 } & C354T & High (10) & High (10) & Medium (7) & Medium (9) & Medium (7) & Medium (8) \\
\hline & C8092A & High (11) & Medium (9) & Medium (8) & Medium (9) & & Medium (8) \\
\hline GSTP1 & A313G & Medium (8) & & & Low (6) & Medium (8) & \\
\hline \multirow[t]{2}{*}{ MDR1 } & C3435T & Medium (9) & & & Medium (8) & & Medium (8) \\
\hline & G2677T/A & Medium (7) & & & & & Medium (8) \\
\hline \multirow[t]{2}{*}{$\mathrm{XPD}$} & $\mathrm{A} 2251 \mathrm{C}$ & $\operatorname{High}(12)$ & High (12) & Medium (8) & High (12) & Medium (9) & Medium (9) \\
\hline & G934A & $\operatorname{High}(12)$ & Medium (9) & Medium (8) & Medium (9) & Medium (8) & Medium (7) \\
\hline \multirow[t]{2}{*}{$\mathrm{XPG}$} & G3310C & Medium (9) & & & & & \\
\hline & $\mathrm{T} 138 \mathrm{C}$ & Medium (7) & & & & & \\
\hline \multirow[t]{2}{*}{ XRCC1 } & G1196A & Low (6) & High (10) & Medium (8) & Medium (9) & Medium (8) & \\
\hline & C580T & Medium (8) & & & & & \\
\hline $\mathrm{CDA}$ & A79C & Medium (7) & & & & Medium (7) & Low (6) \\
\hline XRCC3 & $\mathrm{C} 18067 \mathrm{~T}$ & High (10) & & & Medium (8) & Medium (8) & \\
\hline
\end{tabular}

chemotherapy response $(\mathrm{OR}=1.90,95 \% \mathrm{CI}: 1.14-3.17$, $P=0.013 ;$ OR $=2.36,95 \%$ CI: $1.30-4.29, P=0.005$, respectively) (Figure 3C and 3D). Patients carrying CC genotype of MDR1 C3435T or GG genotype of MDR1 G2677T/A had better chemotherapy response. There were 11 publications studied association of XRCC1 G1196A [7, $22,36-40,46,50-52]$, but high heterogeneity $(P<0.001$, $\left.\mathrm{I}^{2}=74.3 \%\right)$ and publication bias exist among the studies (Begg's test $P=0.024$; Egger's test $P=0.002$ ). Moreover, it was hardy to determine about the association of XPD A2251C with chemotherapy response for its $95 \%$ CI was $0.99-1.44$. Thus, we made quality assessment about the publications by using quality scoring criteria from Wu's study [26], but it was modified by considering high (or low) quality if the score $>12$ (or $\leq 12$ ) in our analyses. We did quality stratified analyses in SNPs which reported in more than 10 studies. The results showed that XPD A2251C was more likely related to drug response in pooled analysis of high quality publications which included 2625 patients $(\mathrm{OR}=1.22,95 \% \mathrm{CI}: 1.00-1.50, P$ $=0.05)($ Figure $4 \mathrm{~A})$, and XRCC1 G1196A was associated with chemotherapy response in high quality publications with low heterogeneity. $(\mathrm{OR}=0.74,95 \% \mathrm{CI}$ : $0.62-0.89, P$ $=0.001$ ) (Figure 4B).

\section{Quality assessment of meta-analysis results}

The reliability of our meta-analysis results were assessed by the criteria described in Table S2. Score was determined by the following 4 factors: number of included publications, sample size of patients, heterogeneity and publication bias. Total score ranged from 2 to 12 . Metaanalysis results were considered low or medium or high reliability if the score were $2-6$ or $7-9$ or $10-12$. The quality assessment results were described in Table 6. We were exciting to notice that high reliability showed about
XRCC1 G1196A pooled analysis result in high quality studies, while the total pooled analysis result was in low reliability. Moreover, our genotyping study result of XRCC1 G1196A was consistent with the high reliability result.

\section{DISCUSSION}

In this study, we investigated the associations of widely studied SNPs (13 polymorphisms in 8 genes) with platinum-based chemotherapy response in NSCLC patients. We also conducted a comprehensive metaanalysis of these SNPs. Our results showed that XRCC1 G1196A/C580T, and XRCC3 C18067T were significantly correlated with platinum-based chemotherapy. XPD A2251C, MDR1 C3435T and MDR1 G2677T/A, GSTP1 A313G, XPG G3310C, ERCC1 C354T were correlated to platinum-based chemotherapy response in different subgroups.

Platinum-based chemotherapy was widely used for treatment of advanced NSCLC, but pharmacogenomic differences between individuals may affect drug response. In the last several decades, gene polymorphisms were revealed to play an important role in chemotherapy response [24]. Therefore, most studies focused on the polymorphisms of genes involved in DNA repair pathway, transporters, metabolism and detoxification. In this study, we selected 9 SNPs in DNA repair pathway genes, 2 SNPs of transporter genes and 2 from metabolism and detoxification genes. They were extensively studied by researchers but results were not consistent. We used a larger sample size $(n=1024)$ to detect relationships between these SNPs and platinum-based chemotherapy response in NSCLC. Moreover, we conducted a metaanalysis to verify the results. 
DNA repair was one of the classical platinum resistance mechanism [53]. Polymorphisms in genes of DNA repair pathway could affect DNA repair capacity and alter sensitivity to platinum-based chemotherapy. In this study, XRCC1 G1196A was significantly correlated to platinum-based chemotherapy response both in our genotyping study and meta-analysis. XRCC1 C580T and XRCC3 C18067T were also related to the drug response from the meta-analysis. XRCC1 and XRCC3 were both DNA base excision repair (NER) genes. XRCC1 G1196A/
C580T and XRCC3 C18067T were all non-synonymous SNPs. They could directly contribute to gene expression and activity. Increased NER capacity would lead to decrease sensitivity of patients to chemotherapy [54]. A recent meta-analysis conducted by Gao et.al [55] about XRCC1 G1196A and C580T showed consistent result with our findings about XRCC1 C580T, but no significantly association showed about XRCC1 G1196A in their study. We carefully compared the included studies in the two meta-analyses. Most of studies included in

\begin{tabular}{|c|c|c|c|c|c|}
\hline (A) & & & Responders & Non-responde & \\
\hline Studies & XRCC1 C580T & OR $(95 \% \mathrm{CI})$ & CC/TOTAL & CC/TOTAL & Weight \\
\hline Peng (2006) & & $0.43(0.23,0.78)$ & $24 / 72$ & $69 / 128$ & 17.17 \\
\hline $\operatorname{Sun}(2008)$ & & $0.22(0.09,0.58)$ & $8 / 31$ & $39 / 64$ & 10.73 \\
\hline Hong (2009) & & $0.49(0.25,0.96)$ & $19 / 57$ & $54 / 107$ & 15.67 \\
\hline $\mathrm{Xu}(2011)$ & & $0.39(0.18,0.86)$ & $12 / 44$ & $42 / 86$ & 13.34 \\
\hline Zhang (2014) & & $0.99(0.65,1.53)$ & $60 / 127$ & $118 / 249$ & 21.40 \\
\hline $\operatorname{Jin}(2014)$ & & $0.73(0.48,1.10)$ & $71 / 144$ & $134 / 234$ & 21.69 \\
\hline Overall (I-squared $=61.3 \%, \mathrm{p}=0.024$ ) & & $0.54(0.37,0.80)$ & $194 / 475$ & $456 / 868$ & 100.00 \\
\hline NOTE: Weights are ścon random effects analysis & & & & & \\
\hline$\frac{1}{. \infty m}$ & & 11 & & & \\
\hline (B) & & & Responders & Jon-responder & $\%$ \\
\hline Studies & CC3 C18067T & $\mathrm{OR}(95 \% \mathrm{CI})$ & CC/TOTAL & CC/TOTAL & Weight \\
\hline Joerger (2011) & & $0.37(0.16,0.86)$ & $9 / 42$ & $40 / 94$ & 16.96 \\
\hline $\mathrm{Xu}(2011)$ & - & $0.46(0.16,1.33)$ & $36 / 44$ & $78 / 86$ & 8.39 \\
\hline Ludovini (2011) & - & $0.62(0.31,1.24)$ & $15 / 62$ & $43 / 127$ & 18.68 \\
\hline Liao(2012) $\leftarrow$ & & $0.88(0.07,10.31)$ & $18 / 19$ & $41 / 43$ & 1.16 \\
\hline Chen (2012) & $\rightarrow$ & $1.21(0.55,2.69)$ & $87 / 96$ & $215 / 242$ & 10.00 \\
\hline $\operatorname{Sin}(2014)$ & - & $0.75(0.50,1.14)$ & $64 / 145$ & 120/234 & 44.81 \\
\hline Overall (I-squared $=0.0 \%, p=0.427$ ) & & $0.69(0.52,0.91)$ & $229 / 40 \mathrm{~S}$ & $537 / 826$ & 100.00 \\
\hline
\end{tabular}

Figure 2: Meta-analysis of associations of XRCC1 C580T and XRCC3 C18067T with platinum-based chemotherapy response in NSCLC patients. 


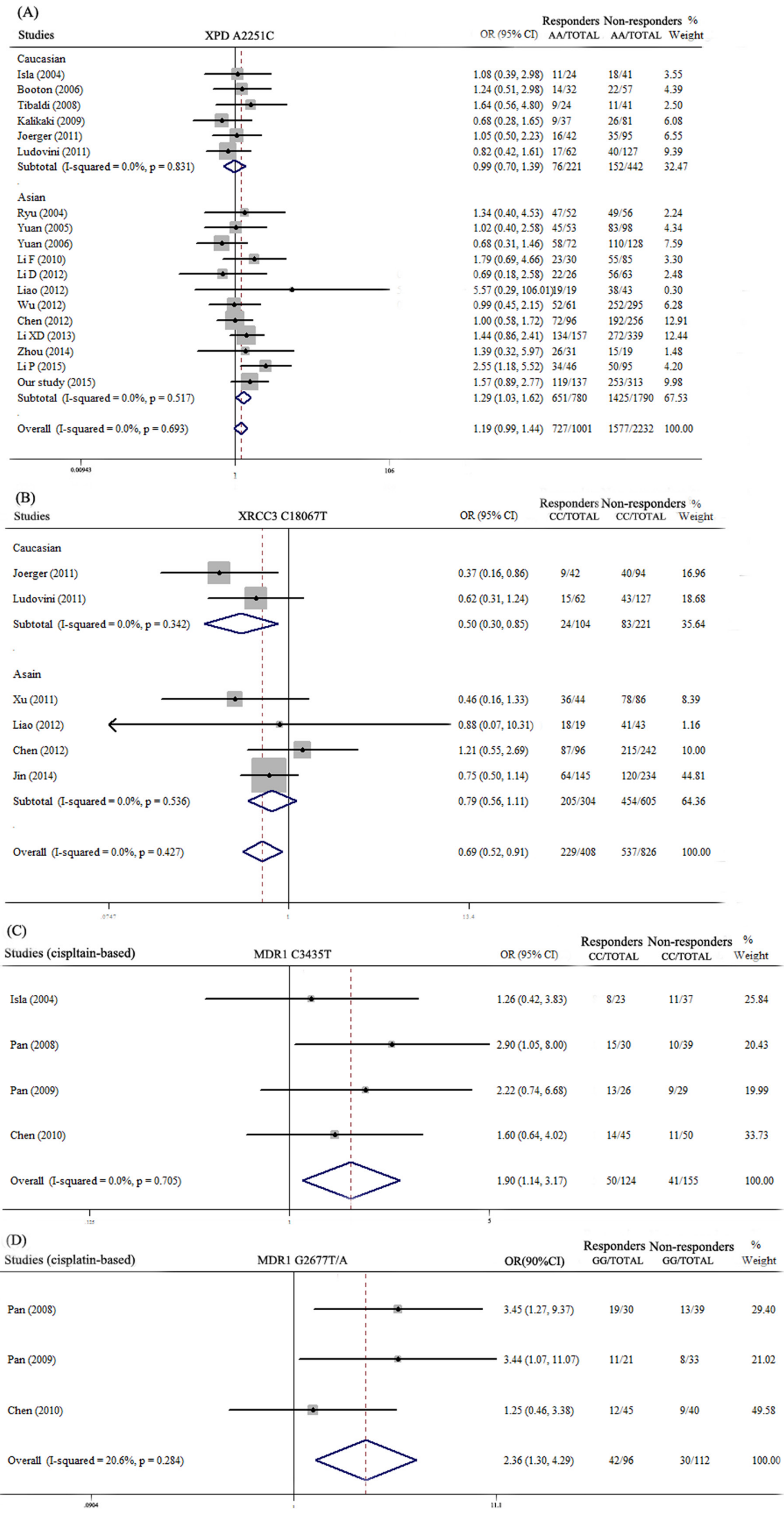

Figure 3: Meta-analysis of association polymorphisms of chemotherapy response in different subgroups. 
(A) Studies XPD A2251C

High quality Isla (2004)

Ryu (2004)

Yuan (2005)

Yuan (2006)

Tibaldi (2008)

Li F (2010)

Ludovini (2011)

Joerger (2011)

Wu (2012)

Chen (2012)

LiX (2013)

Li P (2015)

Our study (2015)

Subtotal (I-squared $=0.0 \%, \mathrm{p}=0.590$ )

Low quality

Booton (2006)

Kalikaki (2009)

Liao (2012)

Li DR (2012)

Zhou (2014)

Subtotal (I-squared $=0.0 \%, p=0.596$ )

Overall (I-squared $=0.0 \%, p=0.693$ )

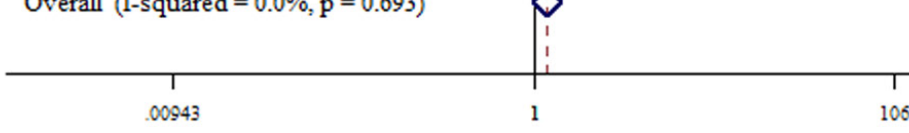

(B) Studies

XRCC1 G1196A

106

High quality

Hong (2009)

Joerger (2011)

Zhang (2014)

$\operatorname{Jin}(2014)$

Peng (2014)

Our study (2015)

Subtotal (I-squared $=37.9 \%, p=0.153$ )

Low quality

Sun (2008)

Kalikaki (2009)

$\mathrm{Xu}$ (2011)

Zhou (2011)

Li D (2011)

Liao (2012)

Subtotal (I-squared $=49.3 \%, p=0.079$ )

Overall (I-squared $=74.3 \%, \mathrm{p}=0.000$ )

\begin{tabular}{r|lll}
\hline & \\
\hline & \\
\hline
\end{tabular}

Overall (I-squared $=74.3 \%, p=0.000)$

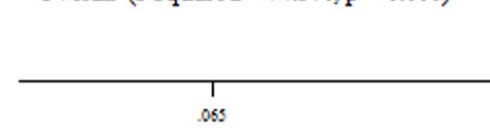

Responders Non-responders $\%$
OR $(95 \%$ CI $)$ AA/TOTAL AA/TOTAL Weight

$\begin{array}{llll}1.08(0.39,2.98) & 11 / 24 & 18 / 41 & 3.55 \\ 1.34(0.40,4.53) & 47 / 52 & 49 / 56 & 2.24 \\ 1.02(0.40,2.58) & 45 / 53 & 83 / 98 & 4.34 \\ 0.68(0.31,1.46) & 58 / 72 & 110 / 128 & 7.59 \\ 1.64(0.56,4.80) & 9 / 24 & 11 / 41 & 2.50 \\ 1.79(0.69,4.66) & 23 / 30 & 55 / 85 & 3.30 \\ 0.82(0.42,1.61) & 17 / 62 & 40 / 127 & 9.39 \\ 1.05(0.50,2.23) & 16 / 42 & 35 / 95 & 6.55 \\ 0.99(0.45,2.15) & 52 / 61 & 252 / 295 & 6.28 \\ 1.00(0.58,1.72) & 72 / 96 & 192 / 256 & 12.91 \\ 1.44(0.86,2.41) & 134 / 157 & 272 / 339 & 12.44 \\ 2.55(1.18,5.52) & 34 / 46 & 50 / 95 & 4.20 \\ 1.57(0.89,2.77) & 119 / 137 & 253 / 313 & 9.98 \\ 1.22(1.00,1.50) & 637 / 856 & 1420 / 1969 & 85.27\end{array}$

$1.24(0.51,2.98) \quad 14 / 32 \quad 22 / 57 \quad 4.39$

$\begin{array}{llll}0.68(0.28,1.65) & 9 / 37 & 26 / 81 & 6.08\end{array}$

$5.57(0.29,106.01) 19 / 19 \quad 38 / 43 \quad 0.30$

$\begin{array}{llll}0.69(0.18,2.58) & 22 / 26 & 56 / 63 & 2.48\end{array}$

$\begin{array}{llll}1.39(0.32,5.97) & 26 / 31 & 15 / 19 & 1.48\end{array}$

$\begin{array}{llll}1.02(0.61,1.68) & 90 / 145 & 157 / 263 & 14.73\end{array}$

$1.19(0.99,1.44) \quad 727 / 1001 \quad 1577 / 2232 \quad 100.00$

Responders Non-responders \% (9.\%) GG/TOTAL GG/TOTAL Weight

$\begin{array}{llll}1.20(0.63,2.30) & 26 / 57 & 44 / 107 & 5.42 \\ 1.24(0.58,2.64) & 17 / 40 & 34 / 91 & 3.89 \\ 0.62(0.40,0.96) & 49 / 127 & 125 / 248 & 16.95 \\ 0.55(0.36,0.84) & 52 / 144 & 119 / 234 & 18.89 \\ 1.02(0.60,1.75) & 40 / 84 & 71 / 151 & 8.67 \\ 0.71(0.52,0.95) & 104 / 229 & 400 / 739 & 33.68 \\ 0.74(0.62,0.89) & 288 / 681 & 793 / 1570 & 87.50\end{array}$

$1.00(0.38,2.65) \quad 14 / 23 \quad 39 / 64 \quad 2.63$

$\begin{array}{llll}1.21(0.51,2.86) & 11 / 37 & 21 / 81 & 3.02\end{array}$

$2.98(1.38,6.40) \quad 30 / 44 \quad 36 / 86 \quad 2.53$

$3.91(1.46,10.51) 29 / 35 \quad 42 / 76 \quad 1.48$

$5.42(1.91,15.39) 20 / 26 \quad 24 / 63 \quad 1.05$

$\begin{array}{llll}1.38(0.46,4.09) & 9 / 19 & 17 / 43 & 1.79\end{array}$

$2.22(1.54,3.21) \quad 113 / 184 \quad 179 / 413 \quad 12.50$

$0.93(0.79,1.09) \quad 401 / 865 \quad 972 / 1983 \quad 100.00$

Figure 4: Meta-analysis of association polymorphisms of chemotherapy response after quality assessment of studies. 
their meta-analysis were small sample size studies, and they also included the studies with patients received radiotherapy which we excluded [56, 57]. For DNA repair gene polymorphisms, additionally, we also found that XRCC3 C18067T showed contribution to drug response in Caucasians and XPD A2251C was related to the response in Asian population. Allele frequency usually different between races, and racial differences were important factors for drug response $[58,59]$. We did not find any statistical evidence for associations between the other SNPs (ERCC1 C354T/C8092A, XPD G934A and XPG G3310C/T138C) in DNA repair pathway and drug response in the meta-analysis. In our genotyping study, these polymorphisms also showed no significant correlations to platinum-based chemotherapy response in the overall analysis.

Transporters involved in drug resistance by decrease uptake or efflux of the drugs by the proteins known as ATP binding cassette transporters [60]. MDR1 also named ABCB1, it encodes P-glycoprotein which is an ATPdependent drug efflux. It is responsible for decreased drug accumulation and often mediates the development of resistance to anticancer drug [61-63]. We found that both MDR1 C3435T and G2677T/A were associated with cisplatin-based chemotherapy response from the results of meta-analysis. However, the numbers of subjects pooled for these two SNPs in cisplatin-based chemotherapy subgroup were small. We considered that these associations maybe need further investigations. Additionally, there were several findings in our genotyping study about the SNPs. Both MDR1 C3535T and $\mathrm{G} 2766 \mathrm{~T} / \mathrm{A}$ were associated with platinum-based chemotherapy response in females, and MDR1 C3435T also related to platinum response in AC patients.

GSPT1 and CDA were metabolism and detoxification pathway genes. GSTP1 was a member of GST family. It mediates formation of platinum-glutathione adduct [64] which decreased chemotherapy sensitivity. 7 studies were included in GSTP1 A313G pool analysis [51, 52, 65-67], but no significant correlation between this polymorphism and chemotherapy response. However, we found GSTP1 A313G related to platinum-based chemotherapy response of patients with $<55$ year old in our genotyping study. CDA is an enzyme that metabolic inactivation of gemcitabine [68]. The patients in 4 studies of CDA A79C were received platinum-gemcitabine treatment $[7,41,45,69]$, but no associations were found in the meat-analysis of CDA A79C.

We conducted this study to get comprehensive conclusions about SNPs contributed to platinum-based chemotherapy response in NSCLC patients, but there were several possible limitations. It was unfortunately about the genotyping of XRCC1 C580T and XRCC3 C18067T failed in our samples, thus meta-analyses of these two SNPs were calculated without the results from our genotyping study. In meta-analyses of ERCC1 and MDR1, we did not include the data from the studies by Krawczyk et al. [70] and Du et al. [71] because they classified SD patients as responders. Our meta-analysis mainly used unadjusted estimates because not all publications presented their adjusted estimates. Finally, we attempted to conduct meta-analysis in each subgroup, but the other publications did not conduct subgroup analysis, or when they did but not in the same way. Thus, we cannot do pool analyses in the subgroups.

It was our first attempt to evaluate the quality of meta-analysis results. Only ERCC1 C3435T/C8092A, XPD A2251C/G934A, XRCC1 G1196A and XRCC3 $\mathrm{C} 18067 \mathrm{~T}$ showed high reliability. It means the other SNPs may need more investigations, though most of them showed medium reliability. In conclusion, contributions of XRCC1 G1196A/C580T and XRCC3 C18067T to drug response were further confirmed by our large sample size genotyping study and comprehensive meta-analysis. It is meaningful for personalized platinum-based treatment of NSCLC. Studies investigate associations of these SNPs with platinum-based chemotherapy response in NSCLC could be less meaningful after our study.

\section{ACKNOWLEDGMENTS}

This work was supported by the National High-tech R\&D Program of China (863 Program) (2012AA02A517), National Natural Science Foundation of China (81373490, 81573508, 81573463), Hunan Provincial Science and Technology Plan of China (2015TP1043), Open Foundation of Innovative Platform in University of Hunan Province of China (2015-14), and the Fundamental Rese arch Funds for the Central Universities of Central South University (2015zzts116).

\section{CONFLICTS OF INTEREST}

The authors declare that they have no conflict of interest.

\section{REFERENCES}

1. Siegel RL, Miller KD and Jemal A. Cancer statistics, 2015. CA Cancer J Clin. 2015; 65:5-29.

2. Lebwohl D and Canetta R. Clinical development of platinum complexes in cancer therapy: an historical perspective and an update. Eur J Cancer. 1998; 34:15221534.

3. Bunn PA, Jr. and Kelly K. New chemotherapeutic agents prolong survival and improve quality of life in non-small cell lung cancer: a review of the literature and future directions. Clinical cancer research. 1998; 4:1087-1100.

4. Chen J, Yin JY, Li XP, Wang Y, Zheng Y, Qian CY, He H, Fang C, Wang Z, Zhang Y, Xiao L, Wang SY, Zhang W, Zhou HH and Liu ZQ. Association of Wnt-Inducible 
Signaling Pathway Protein 1 Genetic Polymorphisms With Lung Cancer Susceptibility and Platinum-Based Chemotherapy Response. Clinical lung cancer. 2015; 16:298-304 e291-292.

5. Li XP, Yin JY, Wang Y, He H, Li X, Gong WJ, Chen J, Qian CY, Zheng Y, Li F, Yin T, Gong ZC, Zhou BT, Zhang Y, Xiao L, Zhou HH, et al. The ATP7B genetic polymorphisms predict clinical outcome to platinum-based chemotherapy in lung cancer patients. Tumour biology. 2014; 35:8259-8265.

6. Wang Y, Yin JY, Li XP, Chen J, Qian CY, Zheng Y, Fu YL, Chen ZY, Zhou HH and Liu ZQ. The association of transporter genes polymorphisms and lung cancer chemotherapy response. PloS one. 2014; 9:e91967.

7. Joerger M, Burgers SA, Baas P, Smit EF, Haitjema TJ, Bard MP, Doodeman VD, Smits PH, Vincent A, Huitema AD, Beijnen JH and Schellens JH. Germline polymorphisms in patients with advanced nonsmall cell lung cancer receiving first-line platinum-gemcitabine chemotherapy: a prospective clinical study. Cancer. 2012; 118:2466-2475.

8. Zhang T, Sun J, Lv M, Zhang L, Wang X, Ren JC and Wang B. XPG is predictive gene of clinical outcome in advanced non-small-cell lung cancer with platinum drug therapy. Asian Pacific journal of cancer prevention. 2013; 14:701-705.

9. Feng J, Sun X, Sun N, Qin S, Li F, Cheng H, Chen B, Cao Y, Ma J, Cheng L, Lu Z, Ji J and Zhou Y. XPA A23G polymorphism is associated with the elevated response to platinum-based chemotherapy in advanced non-small cell lung cancer. Acta biochimica et biophysica Sinica. 2009; 41:429-435.

10. Chen S, Huo X, Lin Y, Ban H, Li W, Zhang B, Au WW and $\mathrm{Xu}$ X. Association of MDR1 and ERCC1 polymorphisms with response and toxicity to cisplatin-based chemotherapy in non-small-cell lung cancer patients. International journal of hygiene and environmental health. 2010; 213:140-145.

11. Isla D, Sarries C, Rosell R, Alonso G, Domine M, Taron M, Lopez-Vivanco G, Camps C, Botia M, Nunez L, SanchezRonco M, Sanchez JJ, Lopez-Brea M, Barneto I, Paredes A, Medina B, et al. Single nucleotide polymorphisms and outcome in docetaxel-cisplatin-treated advanced non-smallcell lung cancer. Annals of oncology. 2004; 15:1194-1203.

12. Booton R, Ward T, Heighway J, Taylor P, Power F, Ashcroft L, Morris J and Thatcher N. Xeroderma pigmentosum group D haplotype predicts for response, survival, and toxicity after platinum-based chemotherapy in advanced nonsmall cell lung cancer. Cancer. 2006; 106:2421-2427.

13. Pan JH, Han JX, Wu JM, Huang HN, Yu QZ and Sheng LJ. MDR1 single nucleotide polymorphism G2677T/A and haplotype are correlated with response to docetaxelcisplatin chemotherapy in patients with non-small-cell lung cancer. Respiration. 2009; 78:49-55.

14. Krawczyk P, Wojas-Krawczyk K, Mlak R, Kucharczyk T,
Biernacka B and Milanowski J. Predictive value of ERCC1 single-nucleotide polymorphism in patients receiving platinum-based chemotherapy for locally-advanced and advanced non-small cell lung cancer-a pilot study. Folia histochemica et cytobiologica. 2012; 50:80-86.

15. Yan PW, Huang XE, Yan F, Xu L and Jiang Y. Influence of MDR1 gene codon 3435 polymorphisms on outcome of platinum-based chemotherapy for advanced non small cell lung cancer. Asian Pacific journal of cancer prevention. 2011; 12:2291-2294.

16. Wang J, Zhang Q, Zhang H, Wang Q, Yang X, Gu Y and Zhang S. [Association between polymorphisms of ERCC1 and response in patients with advanced non-small cell lung cancer receiving cisplatin-based chemotherapy]. [Article in Chinese]. Zhongguo fei ai za zhi. 2010; 13:337-341.

17. Hong W, Wang K, Zhang YP, Kou JY, Hong D, $\mathrm{Su}$ D, Mao WM, Yu XM, Xie FJ and Wang XJ. Methylenetetrahydrofolate reductase C677T polymorphism predicts response and time to progression to gemcitabinebased chemotherapy for advanced non-small cell lung cancer in a Chinese Han population. Journal of Zhejiang University Science B. 2013; 14:207-215.

18. Pan JH, Han JX, Wu JM, Sheng LJ, Huang HN and Yu QZ. MDR1 single nucleotide polymorphisms predict response to vinorelbine-based chemotherapy in patients with non-small cell lung cancer. Respiration. 2008; 75:380-385.

19. Huang SJ, Wang YF, Jin ZY, Sun JY and Guo ZL. Role of ERCC1 variants in response to chemotherapy and clinical outcome of advanced non-small cell lung cancer. Tumour biology. 2014; 35:4023-4029.

20. Zhao X, Zhang Z, Yuan Y and Yuan X. Polymorphisms in ERCC1 gene could predict clinical outcome of platinumbased chemotherapy for non-small cell lung cancer patients. Tumour biology. 2014; 35:8335-8341.

21. Li F, Sun X, Sun N, Qin S, Cheng H, Feng J, Chen B, Cheng L, Lu Z, Ji J and Zhou Y. Association between polymorphisms of ERCC1 and XPD and clinical response to platinum-based chemotherapy in advanced non-small cell lung cancer. American journal of clinical oncology. 2010; 33:489-494.

22. Liao WY, Shih JY, Chang GC, Cheng YK, Yang JC, Chen YM and Yu CJ. Genetic polymorphism of XRCC1 Arg399Gln is associated with survival in non-small-cell lung cancer patients treated with gemcitabine/platinum. Journal of thoracic oncology. 2012; 7:973-981.

23. KimCurran V, Zhou C, Schmid-Bindert G, Shengxiang R, Zhou S, Zhang L and Zhang J. Lack of correlation between ERCC1 (C8092A) single nucleotide polymorphism and efficacy/toxicity of platinum based chemotherapy in Chinese patients with advanced non-small cell lung cancer. Advances in medical sciences. 2011; 56:30-38.

24. Hildebrandt MA, Gu J and Wu X. Pharmacogenomics of platinum-based chemotherapy in NSCLC. Expert opinion on drug metabolism \& toxicology. 2009; 5:745-755. 
25. Cui Z, Yin Z, Li X, Wu W, Guan P and Zhou B. Association between polymorphisms in XRCC1 gene and clinical outcomes of patients with lung cancer: a meta-analysis. BMC cancer. 2012; 12:71.

26. Wu J, Liu J, Zhou Y, Ying J, Zou H, Guo S, Wang L, Zhao N, Hu J, Lu D, Jin L, Li Q and Wang JC. Predictive value of XRCC1 gene polymorphisms on platinum-based chemotherapy in advanced non-small cell lung cancer patients: a systematic review and meta-analysis. Clinical cancer research. 2012; 18:3972-3981.

27. Eisenhauer EA, Therasse P, Bogaerts J, Schwartz LH, Sargent D, Ford R, Dancey J, Arbuck S, Gwyther S, Mooney M, Rubinstein L, Shankar L, Dodd L, Kaplan R, Lacombe D and Verweij J. New response evaluation criteria in solid tumours: revised RECIST guideline (version 1.1). Eur J Cancer. 2009; 45:228-247.

28. Purcell S, Neale B, Todd-Brown K, Thomas L, Ferreira MA, Bender D, Maller J, Sklar P, de Bakker PI, Daly MJ and Sham PC. PLINK: a tool set for whole-genome association and population-based linkage analyses. American journal of human genetics. 2007; 81:559-575.

29. Bagos PG and Nikolopoulos GK. A method for metaanalysis of case-control genetic association studies using logistic regression. Statistical applications in genetics and molecular biology. 2007; 6:Article17.

30. DerSimonian R and Kacker R. Random-effects model for meta-analysis of clinical trials: an update. Contemporary clinical trials. 2007; 28:105-114.

31. Mantel N and Haenszel W. Statistical aspects of the analysis of data from retrospective studies of disease. Journal of the National Cancer Institute. 1959; 22:719-748.

32. Higgins JP, Thompson SG, Deeks JJ and Altman DG. Measuring inconsistency in meta-analyses. BMJ. 2003; 327:557-560.

33. Begg $\mathrm{CB}$ and Mazumdar M. Operating characteristics of a rank correlation test for publication bias. Biometrics. 1994; 50:1088-1101.

34. Egger M, Davey Smith G, Schneider M and Minder C. Bias in meta-analysis detected by a simple, graphical test. BMJ. 1997; 315:629-634.

35. Yuan P, Miao XP, Zhang XM, Wang ZH, Tan W, Sun Y, Zhang XR, Xu BH and Lin DX. [XRCC1 and XPD genetic polymorphisms predict clinical responses to platinum-based chemotherapy in advanced non-small cell lung cancer]. [Article in Chinese]. Zhonghua zhong liu za zhi. 2006; 28:196-199.

36. Jin ZY, Zhao XT, Zhang LN, Wang Y, Yue WT and Xu SF. Effects of polymorphisms in the XRCC1, XRCC3, and XPG genes on clinical outcomes of platinum-based chemotherapy for treatment of non-small cell lung cancer. Genetics and molecular research. 2014; 13:7617-7625.

37. Zhang L, Ma W, Li Y, Wu J and Shi GY. Pharmacogenetics of DNA repair gene polymorphisms in non-small-cell lung carcinoma patients on platinum-based chemotherapy.
Genetics and molecular research. 2014; 13:228-236.

38. Sun X, Li F, Sun N, Shukui Q, Baoan C, Jifeng F, Lu $\mathrm{C}$, Zuhong L, Hongyan C, YuanDong C, Jiazhong J and Yingfeng Z. Polymorphisms in XRCC1 and XPG and response to platinum-based chemotherapy in advanced nonsmall cell lung cancer patients. Lung Cancer. 2009; 65:230236.

39. Xu C, Wang X, Zhang Y and Li L. [Effect of the XRCC1 and XRCC3 genetic polymorphisms on the efficacy of platinum-based chemotherapy in patients with advanced non-small cell lung cancer]. [Article in Chinese]. Zhongguo fei ai za zhi. 2011; 14:912-917.

40. Hong CY, Xu Q, Yue Z, Zhang Y and Yuan Y. [Correlation of the sensitivity of NP chemotherapy in non-small lung cancer with DNA repair gene XRCC1 polymorphism]. [Article in Chinese]. Ai zheng. 2009; 28:1291-1297.

41. Ludovini V, Floriani I, Pistola L, Minotti V, Meacci M, Chiari R, Garavaglia D, Tofanetti FR, Flacco A, Siggillino A, Baldelli E, Tonato $\mathrm{M}$ and Crino L. Association of cytidine deaminase and xeroderma pigmentosum group D polymorphisms with response, toxicity, and survival in cisplatin/gemcitabine-treated advanced non-small cell lung cancer patients. Journal of thoracic oncology. 2011; 6:20182026.

42. Chen X, Sun H, Ren S, Kim Curran V, Zhang L, Zhou S, Zhang J and Zhou C. Association of XRCC3 and XPD751 SNP with efficacy of platinum-based chemotherapy in advanced NSCLC patients. Clinical \& translational oncology. 2012; 14:207-213.

43. Li P, Wang YD, Cheng J, Chen JC and Ha MW. Association between polymorphisms of BAG-1 and XPD and chemotherapy sensitivity in advanced non-small-cell lung cancer patients treated with vinorelbine combined cisplatin regimen. Tumour biology. 2015; 36:9465-9473.

44. Ryu JS, Hong YC, Han HS, Lee JE, Kim S, Park YM, Kim $\mathrm{YC}$ and Hwang TS. Association between polymorphisms of ERCC1 and XPD and survival in non-small-cell lung cancer patients treated with cisplatin combination chemotherapy. Lung Cancer. 2004; 44:311-316.

45. Zhou M, Ding YJ, Feng Y, Zhang QR, Xiang Y and Wan HY. Association of xeroderma pigmentosum group D (Asp312Asn, Lys751Gln) and cytidine deaminase (Lys27Gln, Ala70Thr) polymorphisms with outcome in Chinese non-small cell lung cancer patients treated with cisplatin-gemcitabine. Genetics and molecular research. 2014; 13:3310-3318.

46. Li D, Zhou Q, Liu Y, Yang Y and Li Q. DNA repair gene polymorphism associated with sensitivity of lung cancer to therapy. Med Oncol. 2012; 29:1622-1628.

47. Yuan P, Miao XP, Zhang XM, Wang ZH, Tan W, Sun $\mathrm{Y}, \mathrm{Xu} \mathrm{BH}$ and Lin DX. [Polymorphisms in nucleotide excision repair genes XPC and XPD and clinical responses to platinum-based chemotherapy in advanced non-small cell lung cancer]. [Article in Chinese]. Zhonghua yi xue za zhi. 2005; 85:972-975. 
48. Li XD, Han JC, Zhang YJ, Li HB and Wu XY. Common variations of DNA repair genes are associated with response to platinum-based chemotherapy in NSCLCs. Asian Pacific journal of cancer prevention. 2013; 14:145-148.

49. Wu W, Li H, Wang H, Zhao X, Gao Z, Qiao R, Zhang W, Qian J, Wang J, Chen H, Wei Q, Han B and Lu D. Effect of polymorphisms in XPD on clinical outcomes of platinumbased chemotherapy for Chinese non-small cell lung cancer patients. PloS one. 2012; 7:e33200.

50. Peng Y, Li Z, Zhang S, Xiong Y, Cun Y, Qian C, Li M, Ren T, Xia L, Cheng Y and Wang D. Association of DNA base excision repair genes (OGG1, APE1 and XRCC1) polymorphisms with outcome to platinum-based chemotherapy in advanced nonsmall-cell lung cancer patients. International journal of cancer. 2014; 135:26872696.

51. Kalikaki A, Kanaki M, Vassalou H, Souglakos J, Voutsina A, Georgoulias V and Mavroudis D. DNA repair gene polymorphisms predict favorable clinical outcome in advanced non-small-cell lung cancer. Clinical lung cancer. 2009; 10:118-123.

52. Zhou F, Yu Z, Jiang T, Lv H, Yao R and Liang J. Genetic polymorphisms of GSTP1 and XRCC1: prediction of clinical outcome of platinum-based chemotherapy in advanced non-small cell lung cancer (NSCLC) patients. Swiss medical weekly. 2011; 141:w13275.

53. Amable L. Cisplatin resistance and opportunities for precision medicine. Pharmacological research. 2016.

54. O'Grady S, Finn SP, Cuffe S, Richard DJ, O'Byrne KJ and Barr MP. The role of DNA repair pathways in cisplatin resistant lung cancer. Cancer treatment reviews. 2014; 40:1161-1170.

55. Gu AQ, Wang WM, Chen WY, Shi CL, Lu JH and Han JQ. XRCC1 genetic polymorphisms and sensitivity to platinumbased drugs in non-small cell lung cancer: an update metaanalysis based on 4708 subjects. International journal of clinical and experimental medicine. 2015; 8:145-154.

56. Sullivan I, Salazar J, Majem M, Pallares C, Del Rio E, Paez D, Baiget M and Barnadas A. Pharmacogenetics of the DNA repair pathways in advanced non-small cell lung cancer patients treated with platinum-based chemotherapy. Cancer letters. 2014; 353:160-166.

57. Lee SY, Kang HG, Yoo SS, Kang YR, Choi YY, Lee WK, Choi JE, Jeon HS, Shin KM, Oh IJ, Kim KS, Lee J, Cha SI, Kim CH, Kim YC and Park JY. Polymorphisms in DNA repair and apoptosis-related genes and clinical outcomes of patients with non-small cell lung cancer treated with firstline paclitaxel-cisplatin chemotherapy. Lung Cancer. 2013; 82:330-339

58. Zhou HH, Koshakji RP, Silberstein DJ, Wilkinson GR and Wood AJ. Altered sensitivity to and clearance of propranolol in men of Chinese descent as compared with American whites. The New England journal of medicine. 1989; 320:565-570.
59. Wood AJ and Zhou HH. Ethnic differences in drug disposition and responsiveness. Clinical pharmacokinetics. 1991; 20:350-373.

60. Mazerska Z, Mroz A, Pawlowska M and Augustin E. The role of glucuronidation in drug resistance. Pharmacology \& therapeutics. 2016.

61. Kim HJ, Lee KY, Kim YW, Choi YJ, Lee JE, Choi CM, Baek IJ, Rho JK and Lee JC. P-glycoprotein confers acquired resistance to 17-DMAG in lung cancers with an ALK rearrangement. BMC cancer. 2015; 15:553.

62. Huang YS, Xue Z and Zhang H. Sorafenib reverses resistance of gastric cancer to treatment by cisplatin through down-regulating MDR1 expression. Med Oncol. 2015; 32:470.

63. Subhani S, Jayaraman A and Jamil K. Homology modelling and molecular docking of MDR1 with chemotherapeutic agents in non-small cell lung cancer. Biomedicine \& pharmacotherapy. 2015; 71:37-45.

64. Stewart DJ. Mechanisms of resistance to cisplatin and carboplatin. Critical reviews in oncology/hematology. 2007; 63:12-31.

65. Booton R, Ward T, Heighway J, Ashcroft L, Morris J and Thatcher N. Glutathione-S-transferase P1 isoenzyme polymorphisms, platinum-based chemotherapy, and nonsmall cell lung cancer. Journal of thoracic oncology. 2006; 1:679-683.

66. Sun N, Sun X, Chen B, Cheng H, Feng J, Cheng L and Lu Z. MRP2 and GSTP1 polymorphisms and chemotherapy response in advanced non-small cell lung cancer. Cancer chemotherapy and pharmacology. 2010; 65:437-446.

67. Lv H, Han T, Shi X, Yao Y, Qiu W, Yue L and Liang J. Genetic polymorphism of GSTP1 and ERCC1 correlated with response to platinum-based chemotherapy in non-small cell lung cancer. Med Oncol. 2014; 31:86.

68. Danesi R, Altavilla G, Giovannetti E and Rosell R. Pharmacogenomics of gemcitabine in non-small-cell lung cancer and other solid tumors. Pharmacogenomics. 2009; 10:69-80.

69. Tibaldi C, Giovannetti E, Vasile E, Mey V, Laan AC, Nannizzi S, Di Marsico R, Antonuzzo A, Orlandini C, Ricciardi S, Del Tacca M, Peters GJ, Falcone A and Danesi R. Correlation of CDA, ERCC1, and XPD polymorphisms with response and survival in gemcitabine/cisplatin-treated advanced non-small cell lung cancer patients. Clinical cancer research. 2008; 14:1797-1803.

70. Krawczyk P, Kucharczyk T, Kowalski DM, Powrozek T, Ramlau R, Kalinka-Warzocha E, Winiarczyk K, Knetki-Wroblewska M, Wojas-Krawczyk K, Kalakucka K, Dyszkiewicz W, Krzakowski M and Milanowski J. Polymorphisms in TS, MTHFR and ERCC1 genes as predictive markers in first-line platinum and pemetrexed therapy in NSCLC patients. Journal of cancer research and clinical oncology. 2014; 140:2047-2057. 
71. Du Y, Su T, Zhao L, Tan X, Chang W, Zhang H and Cao G. Associations of polymorphisms in DNA repair genes and MDR1 gene with chemotherapy response and survival of non-small cell lung cancer. PloS one. 2014; 9:e99843. 